\title{
CONSTRUCTED WETLAND SYSTEMS IN THE UK - THE CWA DATABASE RESOURCE
}

\author{
Peter Randerson ${ }^{1}$ \\ Paul Cooper ${ }^{2}$ \\ ${ }^{\text {IS }}$ chool of Biosciences, Cardiff University, UK \\ ${ }^{2}$ PFC Consulting, The Ladder House, Cheap Street, \\ Chedworth, GL54 4AB, UK
}

\begin{abstract}
There are now believed to be more than 1,200 Constructed Wetland systems (CWs) in the UK. The Constructed Wetland Association (CWA) was formed in 1999 by a group of experienced, reputable designers and constructors to bring together best UK practice. CWA is now responsible for a database of design and performance relating to a range of systems (bed types and applications), which now contains information from more than 1,000 beds. CWA members are encouraged to contribute data to the database, which has been updated 9 times since it was first created in 1999. Most of these sites treat sewage/domestic wastewater but the database also includes examples of systems for the treatment of minewater, sludge, landfill leachate, industrial effluents, surface runoff and road runoff. Particular treatment applications are illustrated by Case Studies, summary articles describing design, construction and performance. For beds with data on influent and effluent concentrations and flow rates, the user can fit four alternative models, to derive reaction rate constants $(K)$, enabling some degree of quantitative comparison of the pollutant reduction performance for different system designs. Access to the database is the main benefit of CWA membership: new members from outside UK are welcome (www.constructedwetland.org).
\end{abstract}

\section{KEYWORDS}

Constructed Wetlands; Reed Beds; database; design; models; performance data; case studies; sewage treatment; tertiary treatment; wastewater treatment.

\section{INTRODUCTION}

Over the past 20 years, constructed wetlands (CWs) have become accepted as a relatively inexpensive, low maintenance "green" technology for wastewater and leachate treatment $[1,7$, 12]. Pollutants are removed from wastewater in the wetlands by a complex variety of physicochemical and biological processes $[3,10]$. Although a large number of CWs have been built worldwide, the mechanisms for removal of organic matter and inorganic nutrients in these systems is poorly understood [11]. In the UK, it is thought that over 1200 such systems have been created [2]. The Constructed Wetland Association (CWA) was formed in 1999, by a group of experienced, reputable designers, constructors, water company operators, researchers and plant suppliers, with the aim of maintaining high standards in the new industry. CWA organises meetings, training courses, promotional events, and maintains a website (www.constructedwetland.org), as well as a database detailing the CW systems in the UK. The website provides authoritative information on CWs and advice to potential customers for services in CW design and construction, and for plants and equipment [2]. Applicants for 
membership of CWA must demonstrate technical and financial competence as practitioners in $\mathrm{CW}$ technology, or with academic publications. To help maintain the reputation of $\mathrm{CW}$ systems and to promote confidence among potential users, CWA members are asked to contribute design and performance data to a central resource of information on best UK practice. This serves to demonstrate the capability of $\mathrm{CW}$ technology in a wide range of applications, including treatment of sewage/domestic wastewater minewater, sludge, landfill leachate, industrial effluents, surface and road runoff.

\section{THE CWA UK DATABASE}

The first UK Reed Bed database was compiled as a supplement to a handbook on CW design [6] and contained information on 154 sites. CWA later took over responsibility for the database, and since 2000 it has undergone 9 revisions using data provided by CWA members and UK environmental regulators. The database is constructed with Windows Access (version 2003 and now contains information on 1,012 sites/beds [2, 4]. Researchers from outside the UK showed interest in becoming members in order to gain access to the CWA Database. A decision was taken in 2005 to admit members from outside the UK at a reduced subscription rate and the Association now has members in Australia, the Czech Republic, Italy and USA.

\subsection{Contents of the Database}

The Main Menu (Figure 1) shows the separate sections of the database. The Member/Contact database gives contact details of CWA members and their specialist interests and expertise, as well as other contributors to the database. One key feature of the database is a series of Case Studies. These are Microsoft Word documents containing process descriptions of sites, performance data tables, site diagrams, photographs and references. These are aimed at demonstrating to potential users how a particular wastewater treatment problem has been solved by a CW design.

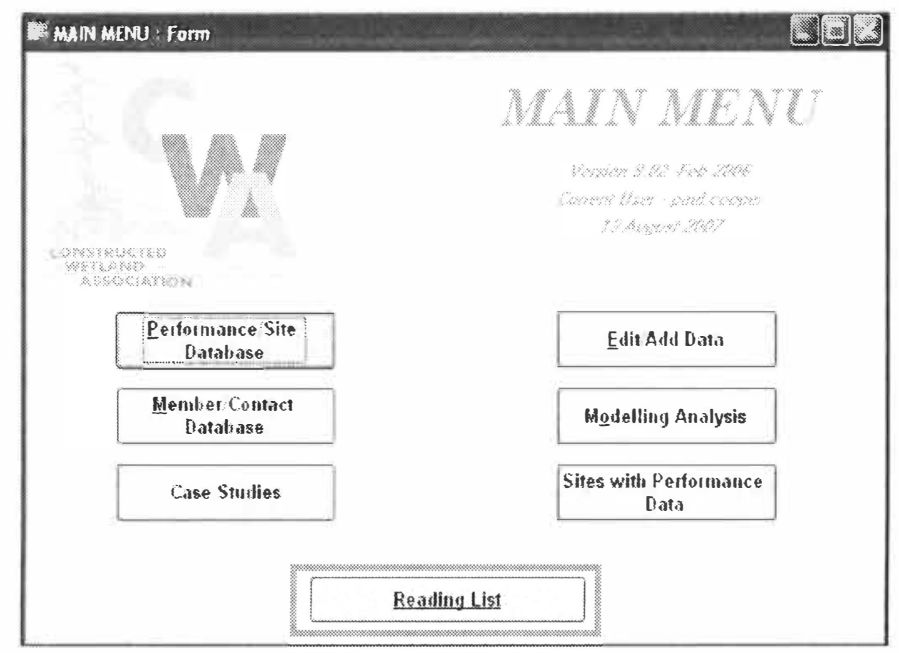

Figure 1. Opening screen showing the sections of the database. 


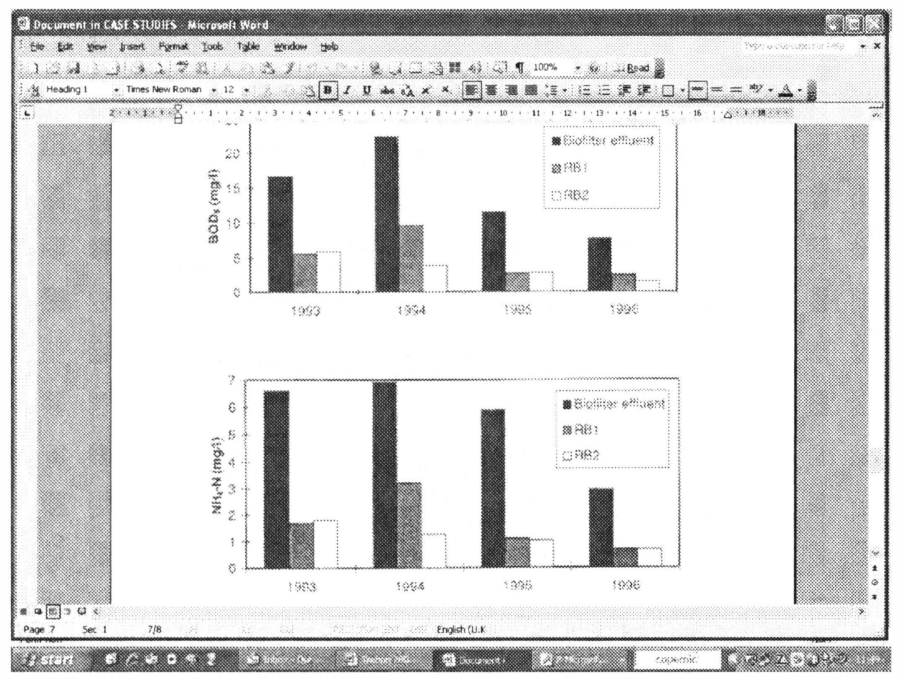

Figure 2. A screen from the Case Study for Tertiary Nitrification in VF beds at WRc Medmenham.

Case Studies are given of the following systems:

- Secondary Sewage Treatment in HF beds

- Tertiary Sewage Treatment in HF beds

- $\quad$ Hybrid systems (VF beds followed by HF beds)

- Tertiary Nitrification in VF beds

- $\quad$ Sludge Drying VF Reed Beds

- $\quad$ Compact VF beds for Secondary treatment

- $\quad$ Separate Storm sewage overflow treatment in HF beds

- $\quad$ Combined Storm sewage overflow + Tertiary treatment in HF beds

Figure 2 shows a summary of performance data from a Case Study for VF Tertiary Nitrification at Water Research centre, Medmenham. The 2-stage vertical flow reed bed design was successful in achieving full nitrification over a 4 year period, allowing discharge to the River Thames, well within consent limits. Table 1 shows the performance of a CVF reed bed system at Will's Barn, Somerset designed to treat septic tank effluent from 9 people $\left(\right.$ area $\left.=4 \mathrm{~m}^{2}\right)$. Excellent reduction is achieved for all parameters, despite the relatively high concentrations in the influent. Oxygen Transfer Rate (OTR) was calculated to be $28 \mathrm{gO}_{2} \mathrm{~m}^{2}$ day $^{-1}$, with the system operating at the average hydraulic loading rate of $39 \mathrm{~mm}^{\text {day }}{ }^{-1}$ [4].

Table 1. Average performance of Will 'sBarn CVF system (18 samples, $\mathrm{mgl}^{-1}$ )

\begin{tabular}{|c|c|c|c|c|c|}
\hline & BOD $_{5}$ & TSS & NH4N & Total N & Total P \\
\hline Influent & 350.8 & 258.1 & 93.9 & 124.5 & 16.6 \\
\hline effluent & 5.0 & 9.8 & 10.3 & 55.8 & 7.7 \\
\hline
\end{tabular}




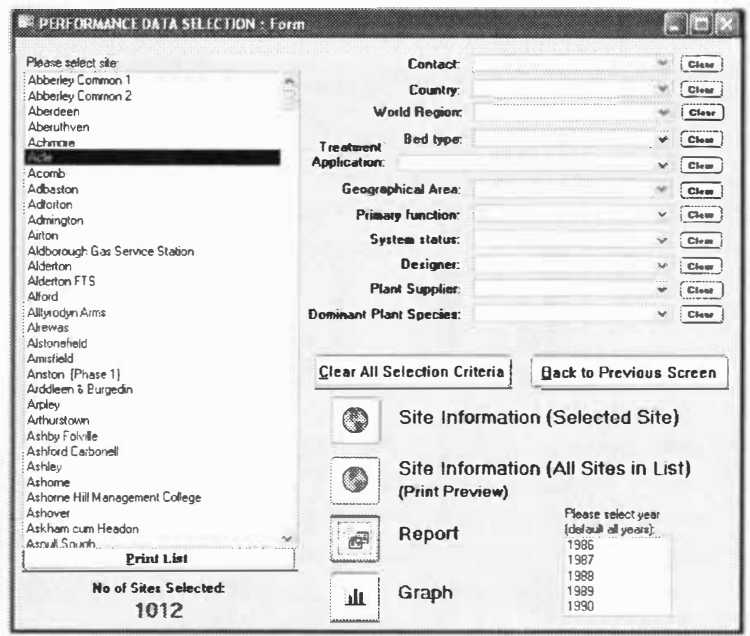

Figure 3. The main screen of the Performance Data Selection form.

A three page Reading List covers the sources of information on wastewater treatment with a particular bias towards UK and European systems and practice. The Performance/Site Database button brings up a screen (Figure 3), which lists 1,012 beds from more than 900 sites in the UK. Of these beds, 201 have some Performance Data but the amount varies widely from data over several years to just occasional records. This Performance Data Selection screen allows the user to select sites to view based on Bed type (Table 2), Treatment Application (Table 2), Geographical area and Designer. The number of sites selected by these criteria is displayed.

Table 2. Breakdown by Bed Type and by Treatment Applications (June 2007)

\begin{tabular}{|c|c|c|c|c|}
\hline Bed Type & 1012 & & Treatment & \\
\hline Secondary sewage Horizontal Flow beds & 107 & & Sewage & 874 \\
\hline Tertiary sewage HF beds & 698 & & Minewater & 50 \\
\hline Vertical Flow (VF) beds & 49 & & Landfill leachate & 24 \\
\hline Compact (CVF) beds & 21 & & Industrial & 19 \\
\hline Hybrid systems (VF + HF) & 19 & & Surface runoff & 16 \\
\hline Storm sewage overflow (separate) & 6 & & Agricultural run-off & 13 \\
\hline $\begin{array}{c}\text { Combined storm sewage overflow } \\
\text { Tertiary }\end{array}$ & 40 & & Road runoff & 6 \\
\hline
\end{tabular}

When a particular site has been selected, details are accessed using the Site Information button, the Report button brings up a spreadsheet showing performance data, and the Graph button allows performance data to be plotted against time (Figure 4). In the 1980s and early 1990s, when CWs were still new and experimental, both influent and effluent composition and flow rates were measured in order to establish design and operating criteria. 


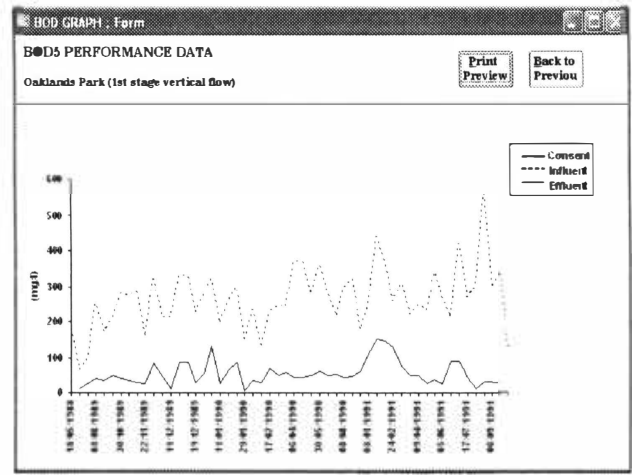

Figure 4. Graph of $\mathrm{BOD}_{5}$ removal for Oaklands Park 1st VF stage from the database.

Now that CWs are regarded as conventional, safe solutions for many treatment applications, only effluent analysis is normally carried out, as required for regulatory compliance [2]. The Add/Edit data screen allows users to add their own data if they have some new material to contribute. The Modelling Analysis function allows a user to model data from a particular site using 4 standard models of pollutant removal kinetics.

\section{MODELLING POLLUTANT REMOVAL}

\subsection{Removal kinetics}

Removal of pollutants in CWs is usually assumed to follow first-order plug flow kinetics [5, 8,9 ], whereby there is a uniform mass flow through the bed from inlet to outlet (HF) or from surface to base (VF). The bed is treated as a bioreactor in which a given pollutant undergoes a constant proportional decline in accordance with the hydraulic residence time.

$C_{1}=C_{0} e^{(-k \text { tr })}$

Equation 1.

Where: $\mathrm{C}_{0}, \mathrm{C}_{1}=$ influent and effluent concentrations respectively $\left(\mathrm{mg} \mathrm{l}^{-1}\right)$; $\operatorname{tr}=$ hydraulic residence time (day); $\mathrm{k}=$ first order reaction rate constant $\left(\right.$ day $\left.^{-1}\right)$. Hence the rate of decline of pollutant concentration depends on the value of $\mathrm{k}$ (Figure 5), which must be determined empirically for a given bed type and conditions such as bed area (A), depth (d), porosity (n) and flow rate $(\mathrm{Q})$.

$\ln \left(C_{1} / C_{0}\right)=-k \operatorname{tr}$

Equation 2.

Reaction rate is typically dependent on the temperature (of sewage in the reed bed). Within the range $15-20^{\circ} \mathrm{C}$ this can be approximated by a linear model $k(T)=a T+b$; where $a$ and $b$ are empirical parameters, and $\mathrm{T}=$ temperature $\left({ }^{\circ} \mathrm{C}\right)[9]$. In a VF bed the input is not a continuous flow, as in HF, but there is rapid drainage producing an unsaturated phase after each pulse of wastewater. $\mathrm{Q}$ is a mean daily value and, although the wastewater is in contact with the bed for a shorter time than if the flow were constant, it may be treated as a plug flow reactor, since $\mathrm{Q}$ is averaged over time. Equation 2 may be used to determine the bed area required to achieve the desired pollutant removal for a given hydraulic residence time (dependent on $\mathrm{Q}, \mathrm{d}, \mathrm{n}$; assuming a value for $\mathrm{k}$ is known from empirical data for $\mathrm{C}_{0}, \mathrm{C}_{1}$ in a similar bed). 


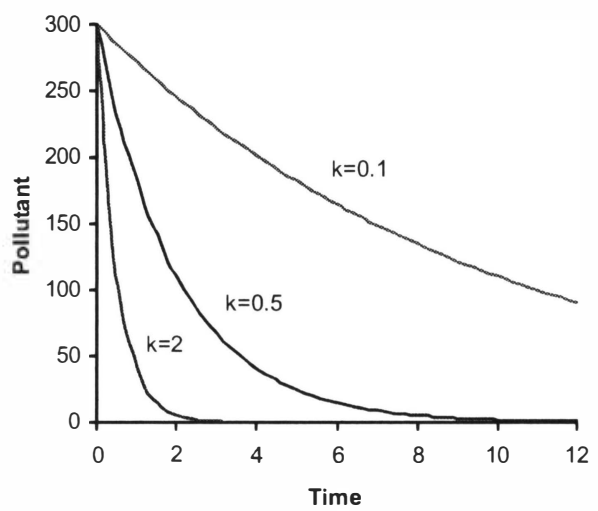

Figure 5. First order kineitcs of pollutant removal

$A=Q\left(\ln C_{1}-\ln C_{0}\right) /(k . d . n)$

Equation 3.

This equation is used in the CWA database [4] in the form

$\mathbf{A}=\mathbf{K}_{\mathbf{1}} \mathbf{Q}\left(\ln \mathbf{C}_{\mathbf{1}}-\ln \mathbf{C}_{\mathbf{0}}\right) \quad$ Equation 4.

Where: $\mathbf{K}_{\mathbf{1}}=\mathbf{1} /(\mathbf{k} . \mathbf{d} . \mathbf{n})$

The constant $K_{1}$ represents the performance of the bed in terms of pollutant removal and is characteristic of its design and operation. Hence it would be desirable to determine the value of $\mathrm{K}_{1}$ from empirical data for $\mathrm{C}_{0}, \mathrm{C}_{1}$ and $\mathrm{Q}$, in order to compare different designs and modes of operation. In the case of the first-order kinetic model, the value of $\mathrm{K}_{1}$ can be determined from the slope of the regression line relating the appropriate measured values of pollutant concentration $\left(\ln C e-\ln C_{0}\right)$, over a range of unit flow rates $(A / Q)$, as shown in Equation 4.

\subsection{Model Fitting in the CWA database}

In the Model Selection screen, the user can select a site or group of sites with similar bed types, which contain performance data for $\mathrm{BOD}_{5}$ (total), $\mathrm{BOD}_{5}$ (dissolved) or $\mathrm{NH}_{3} \mathrm{~N}$. Four alternative models are available for fitting to such data: first order, half order, zero order and Monod kinetics (Figure 6). To be included in the model fit, samples must contain influent and effluent concentrations as well as flow rate, otherwise they are ignored. In each case, the fitted model is displayed as a graph showing all available data points, the (linear) regression line and its associated $\mathrm{R}^{2}$ value (indicating the proportion of total variation explained by the regression) (Figure 7). The value of the reaction constant $\mathrm{K}$, derived from the regression line, is given at the top of the screen (Figure 7). In the first, half, and zero order models, regression lines are forced through the origin, on the assumption that change in pollutant concentration is directly proportional to flow rate.

First order and zero order models tend to give similar results. Zero order kinetics involve absolute reductions of pollutant concentration $\left(\mathrm{C}_{1}-\mathrm{C}_{0}\right)$, rather than proportional declines (ln $\left.\mathrm{C}_{1}-\ln \mathrm{C}_{0}\right)$. 
Similarly, half order kinetics uses the square roots of such concentrations, whereas Monod kinetics incorporates the sum of both proportional and absolute declines (Figure 6). Values of $\mathrm{K}$ are unique to the model from which they were derived. Comparisons should be made between beds or site groups, with respect to the model fitted. Values of $\mathrm{K}$, in effect, summarize the overall performance of the bed over a wide range of conditions.

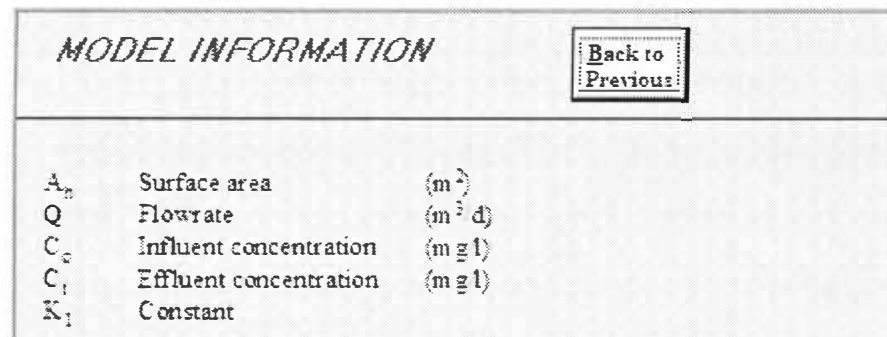

FIRST ORDER KINETICS

$$
A_{i}=K_{1} Q\left(\ln C_{0}-\ln C_{i}\right)
$$

\section{H.HE ORDER KINETICS}

Typtcals.

$$
A_{i}=Q K_{1}\left[C_{z}^{*}-\left(\frac{K_{2}}{C_{i}}\right)^{n}-C_{z}^{*}+\left(\frac{K_{2}}{C_{i}}\right)^{n}\right]
$$

$$
x_{2}=70
$$

ZERO ORDER KIXE TICS

$$
A_{0}=\Lambda_{1} \cup\left(C_{0}-C_{t}\right.
$$

\section{MONOD KINE TICS}

$$
A_{i}=K, O\left[\ln \left(\frac{C_{2}}{C_{i}}\right)+\left(C_{z}-C_{i}\right)\right]
$$

Figure 6. Models available in the CWA database 
Kalmar ECO-TECH '07

KALMAR, SWEDEN, November 26-28, 2007

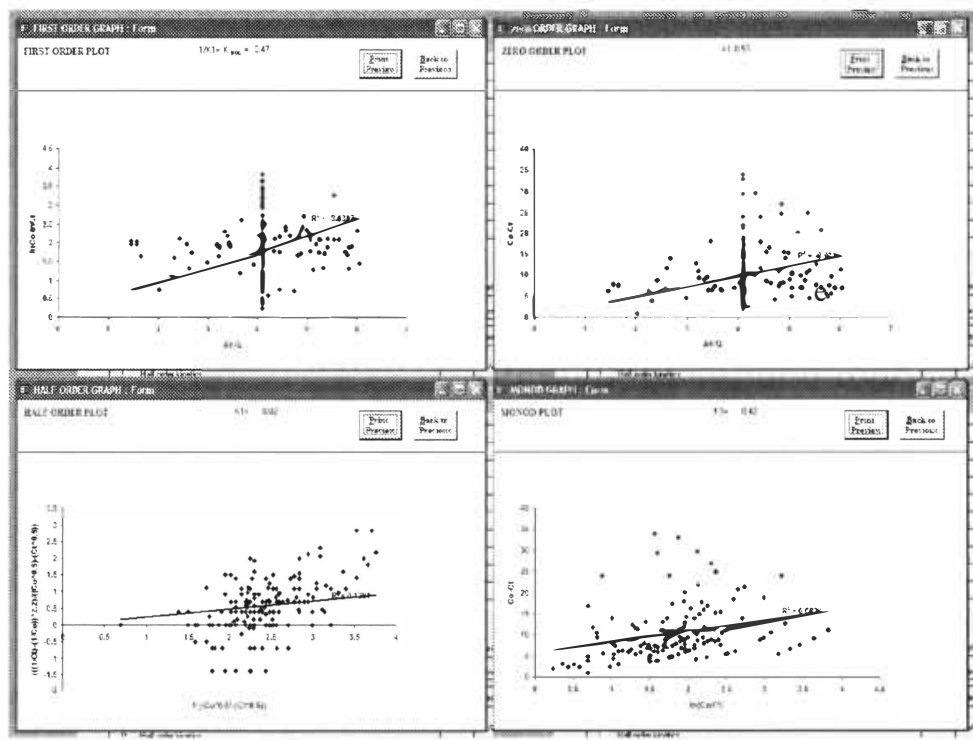

Figure 7. Model fits for Leek Wootton HF tertiary sewage treatment

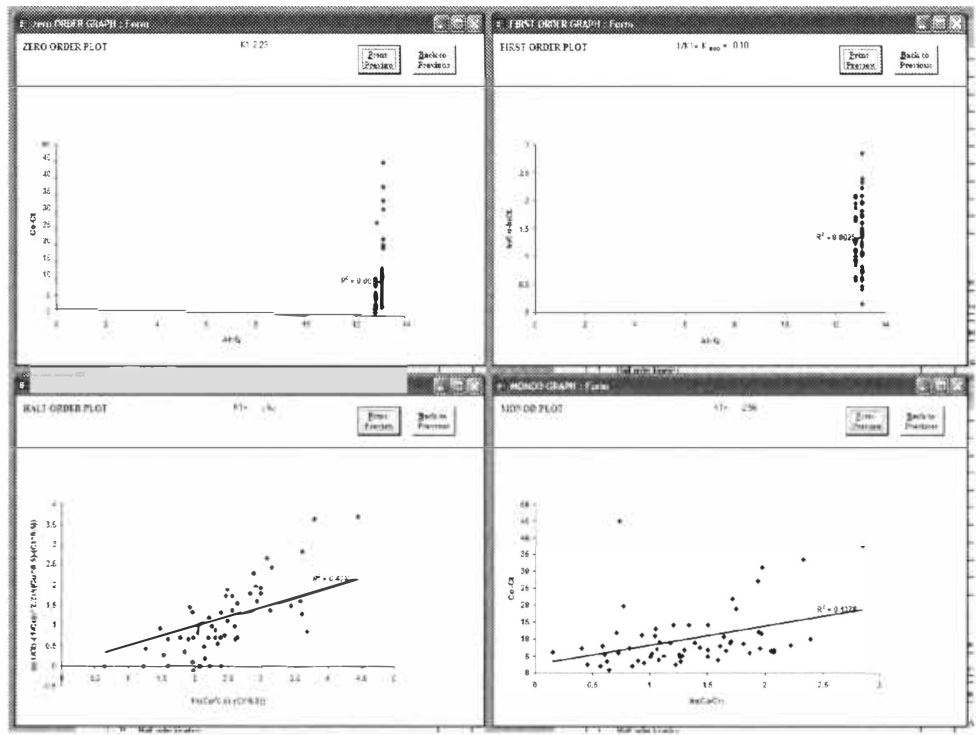

Figure 8. Model fits for WRc Medmenham VF $I^{\text {st }}$ stage tertiary sewage treatment 


\subsection{Examples of model fits using the CWA database (sites described as Case Studies)}

1. Leek Wooton: Horizontal Flow, Tertiary Sewage Treatment (269 performance records) (Figure 7). Note in first and zero order models, records show periods of constant flow (points where $\mathrm{A} / \mathrm{Q}=4.1$ ) and other periods of variable flow rates (both high and low).

2. Water Research Centre, Medmenham: Vertical Flow 1st Stage, Sewage Treatment; Tertiary Nitrification ( 74 performance records) (Figure 8). Note in first and zero order models, records show almost constant flow rates $(\mathrm{A} / \mathrm{Q}=$ approximately 13$)$. In these cases, regression lines are barely visible, but they simply join the origin to the centroid of the points, hence the slope (and the value of $\mathrm{K}$ ) is defined. In the other two models, constant values of $\mathrm{Q}$ are not a problem.

\section{CONCLUSION}

- CWA was formed as a coordinating organisation within the UK water industry in response to poor design by some constructors [2].

- The CWA database has proved a useful tool to the UK water industry as a method of demonstrating what is possible with good design [2].

- The database has collected together basic information from more than 1,000 sites of which about 201 have some performance data [2].

- Case Studies are provided for 9 of the most common design/treatment applications as a method of building confidence in constructed wetland systems [2].

\section{ACKNOWLEDGEMENTS}

We are grateful to Gareth Job, who built the original database, for advice on the database models.

\section{REFERENCES}

[1] Brix, H., 1999. How 'green' are aquaculture, constructed wetlands and conventional wastewater treatment systems? Water Science \& Technology. 40(3), 45-50.

[2] Cooper, P.F., 2006. The Constructed Wetland Association UK constructed wetland database, paper presented to the $10^{\text {th }}$ IW A conference Wetland Systems for Water Pollution Control, Lisbon, Portugal, September, 2006.

[3] Cooper, P.F., Job, G.D., Green, M.B., Shutes, R.B.E., (1996). Reed Beds and Constructed Wetlands for Wastewater Treatment. WRc Swindon, UK. pp202.

[4] CWA, 2006. Constructed Wetland Interactive Database Version 10.01, June 2007, available from Constructed Wetland Association UK (with membership) www.constructedwetland.org.

[5] EPA, 1988. Constructed wetlands and aquatic plant systems for municipal waste water treatment: Design Manual. US EPA Publication 625/1-88/022, Centre for Environmental Research Information, Cincinnati, $\mathrm{OH} 45268$, pp83.

[6] Job, G.D., Green, M.B., Cooper, P.F., 1996. Reed Beds and Constructed Wetlands for Wastewater Treatment, WRc Swindon, UK. June 1996 CD Rom containing data from 154 sites.

[7] Kadlec, R.H., Knight, R.L., 1996. Treatment Wetlands. CRC Press, Boca Raton, FL., USA. 
[8] Kickuth, R., 1981. Abwasserreinigung in Mosaikmatrizen aus anaeroben und aeroben Teilbezierken. Grundlangen der Abwasserreiningung. GWF Schriftreihe Wasser-Abwasser, 19, Oldenburg Verlag, Oldenburg.

[9] Kowalik, P.J., Mierzejewski, M., Randerson P.F., Williams H.G., 2004. Performance of Subsurface Vertical Flow Constructed Wetlands Receiving Municipal Wastewater. Archives of Hydro-Engineering \& Environmental Mechanics, 51(4), 349-370.

[10] Nutall, P.M., Boon, A.G., Rowell, M.R., 1998. Review of the Design and Management of Constructed Wetlands. CIRIA Publ. London UK. 62-67.

[11] Verhoeven, J.T.A., Meuleman, A.F.M., 1999. Wetlands for wastewater treatment: opportunities and limitations. Ecol. Eng. 12, 5-12.

[12] Vymazal, J., Brix, H., Cooper, P.F., Green, M.B., Haberl, R., 1998. Constructed Wetlands for Wastewater Treatment in Europe. Backhuys Publ., Leiden, The Netherlands. pp366. 